\title{
The Approach to Servitization in the Czech Manufacturing Companies
}

\author{
Vladimira VLCKOVA * and Lucie PODSKUBKOVA \\ University of Pardubice, Pardubice, Czech Republic; vladimira.vlckova@upce.cz; \\ lucie.podskubkova@student.upce.cz \\ * Correspondence: vladimira.vlckova@upce.cz
}

\begin{abstract}
Nowadays servitization is an essential part of strategic marketing. Companies can build up a wide portfolio of conventional services, develop/acquire new services or offer advanced services closely connected with the product in the way they provide their customers with ability rather than with a physical value. Unlike foreign professional literature, term servitization appears in in the Czech professional literature sporadically only. It is possible to assume that insufficient cognizance of servitization also shows in the practice of manufacturing companies, i.e. that the service potential is not fully exploited. In this paper a research hypothesis that servitization is applied by manufacturing companies in the Czech Republic as a marketing tool rather than as a way to a change in their strategic focus has been constructed and discussed. The paper outcomes were drawn up based on the analysis, comparison, and synthesis of the information obtained (i) from a targeted research into the professional literature (ii) through an analysis of web pages of 165 selected companies from the point of view of services they offer and (iii) personal experience from interviews conducted at manufacturing companies. The outcomes then should help to identify the opportunities for servitization in manufacturing companies in the Czech Republic.
\end{abstract}

Keywords: servitization; services; manufacturing companies; differentiation of the offerings to customers

JEL Classification: M210; M31

\section{Introduction}

Manufacturing companies are facing a lot of changes in the market environment. In particular, these include globalization, increasing competitiveness of developing countries, and saturation of the market, new technologies, growing customer responsiveness, and changes in the customer demand. The growing competition pushes down profit margins, which requires new income flows and leads, together with commoditization and acceleration of the product innovation cycle, to the fact that more and more manufacturing companies are starting to be interested in connecting their manufacturing activity with provision of customer services. As recent research suggested: The manufacturing companies have a positive reputation with their customers especially thanks to their individual approach to customers and to the flexibility and quality of their services (Jelinkova et al. 2018). They are thus shifting closer and closer to services and some of them so intensively that they are transforming into service providers. Services are understood not only as a strong marketing tool, but they are also becoming a strategic target of a lot of manufacturing companies. A service provided by a manufacturing company is mostly specifically focussed on a particular customer. So, it can be considered as a unique solution to a specific problem. Services provided in the B2B market are much more complex and require administration of a larger number of parameters to ensure their flawless provision and achievement of the desired outcome than those provided in the B2C market (Jackson et al. 2000).

Companies can build up a wide portfolio of conventional services, develop/acquire new services or offer advanced services closely connected with the product in the way they provide their customers with ability rather than with a physical value. In the case of successful implementation, services become a source of income and profits, they make sure the customers are satisfied and they support 
the company growth. This transition from a product-oriented business model to a service-oriented business model is called servitization.

Servitization was first applied in the USA as early as in the 1990s. It has been developing since then, and nowadays it is an essential part of strategic marketing (Baines et al. 2009). Until the end of the 20th century, its content was associated with integration of products and services aiming to fulfil marketing targets, i.e. a marketing approach to servitization. Nowadays, it is associated with a change in the company's strategic focus, i.e. a strategic approach to servitization (Pistoni and Songini 2018). It did not develop until after 2000 (Park et al. 2012).

On a worldwide scale, $38 \%$ of the manufacturing companies can be classified as servitised. In general, "maintenance and support ", and "retail and distribution ", are the most commonly provided services (Mastrogiacomo et al. 2019). Therefore, servitization is a frequent issue among foreign experts. However, unlike foreign professional literature, this term appears in in the Czech professional literature sporadically only (Friedel 2019; Kaňovská 2018). It is possible to assume that insufficient cognizance of servitization also shows in the practice of manufacturing companies. This can also be demonstrated on the outcomes of the conducted own online questioning and the analysis of web pages of selected 49 foundries in the Czech Republic: only a third of the respondents have encountered servitization; $70 \%$ of the respondents stated, after they had been briefly explained what servitization is, that they understand it, and $40 \%$ stated they were already applying this strategy; the companies offer a wide portfolio of mainly conventional services, and only some of them offer advanced services closely connected with a product in cooperation with other supply chain entities (Vlckova and Balasova 2019).

Although as many as $45 \%$ of 2652 manufacturing companies in the Czech Republic engage in services and $2 \%$ of the companies have transformed into service providers (Mastrogiacomo et al. 2019), it is possible to assume that the service potential is not fully exploited. This presumption also supports the results from personal interviews conducted at manufacturing companies mainly in the frame of diploma thesis guidance, e.g. (Balasova 2019). It is possible to expect that the offerings of Czech manufacturers are mostly at the basic or medium levels of the provided services, i.e. for the time being, the companies only endeavour to offer a wide range of conventional services, or they are trying to develop/acquire new services. Most companies still do not offer advanced services closely connected with the product in the way they provide their customers with ability, rather than with a physical value. Therefore, a research hypothesis has been constructed as follows: Servitization is applied by manufacturing companies in the Czech Republic as a marketing tool rather than as a way to a change in their strategic focus.

The following targets were determined to verify this hypothesis (i) to conduct a targeted research into the professional literature aimed at the possible approaches to servitization placing an emphasis on changes in business models applied by manufacturing companies (ii) to conduct an analysis of web pages of randomly selected companies operating in the Czech Republic from the point of view of the services they provide/mention. The outcomes then should help to identify the opportunities for servitization in manufacturing companies in the Czech Republic.

\section{Methodology}

The paper was based on both primary and secondary sources. The secondary sources mainly included foreign professional literature, expert studies, websites of the randomly selected companies from various industry (textile, chemical, petrochemical, rubber, food, engineering, metallurgical, woodworking and construction industry) and information acquired at international conferences. The primary sources the paper drew on were the personal experience from interviews conducted at manufacturing companies in 2018 and 2019 mainly in the frame of diploma thesis guidance. The paper outcomes were drawn up based on the analysis, comparison, and synthesis of the obtained information. 


\section{Results}

\subsection{The marketing approach to servitization}

The marketing approach to servitization is associated with the first interpretations of the term of servitization, where addition of services to products is associated with an increase in the customer value (Vandermerwe and Rada 1988; Kryvinská et al. 2014), with a decrease in the difference between traditional activities of the manufacturer and the service provider (Tellus institut 1999), with the trend of adding more and more service elements to the product offerings (Desmet a kol. 2003). Therefore, the main aim is to differentiate the offerings for customers, whose different possibilities were identified by (Pistoni and Songini 2018). At the same time, they emphasize that products and services can be separated in the mentioned possibilities and sold separately:

- The seller offers for sale a compound package of more products and/or services for more favourable prices compared to the prices of separate components; so-called bundling.

- Mainly B2B market companies sell components as the system selling, e.g. hardware and software. It is a sort of package that should provide the customer with such a combined offer that they would hardly obtain in another way.

- The manufacturer supplements their products with a set of complementary, i.e. presale, sale, and after-sale services; so-called product service.

- Full service represents an offer of a complex package of products and/or services, which satisfies the customer needs and wishes relating to a particular event or problem (Stremersch et al. 2001). It is closely associated with the systems selling. For example, when offering a maintenance service with a delivered facility, the supplier providing the "systems selling" only cooperates with the managers of the customer's maintenance centre, while when providing the "full service" they cooperate, in addition to the above, with the purchase department and with the customers corporate management.

- Offering of the service package includes supporting facilities, facilitation of the product application, information, explicit services (sense experiences, e.g. taste of food) and implicit services (psychological values, e.g. comfort), e.g. sale of wireless internet connection sold as a package including a wi-fi router, installation, information about how to look after the device, hispeed connection (explicit service), a nonstop line for breakdown notification (implicit service). Unlike the bundling, the product-service combination is not a question of choice. The company does not give the customer another choice.

- The last stated offer differentiation possibility is the installed base service. The offer consists of a number of products or services, which are supported with complementary, particularly after-sale services relating to the processes required by the end user for the period of the product lifetime. (Pistoni and Songini 2018; Oliva and Kallenberg 2003). For example, when selling a printer, the manufacturer offers the end user services relating to its operation.

\subsection{The strategic approach to servitization}

The strategic approach to servitization relates to creation of a new form of corporate organization, structure, culture, and managerial controlling systems. This change is usually accompanied by implementation of new technologies and transformation of operating processes in the way to ensure development of the necessary employee knowledge and skills. Therefore, servitization represents innovation of corporate capabilities and processes aiming to make a shift from selling products towards selling a product-service system (hereinafter referred to as the PSS), which better creates the customer and supplier value (Kryvinská et al. 2014). At the same time, companies transform from a product-dominant logic (only goods and information flow between the manufacturer and the customer, the emphasis is placed on product ownership and services are understood as a special type of products) into a service-dominant logic (to integration of the manufacturer's and the customer's resources and to mutual information sharing, the manufacturer helps the customer to achieve their targets, the emphasis is placed on services bringing benefit to the customer) (Eggert et al. 2018; Weijiao 
et al. 2018). This results in creation of new business models, which extend the existing product offerings trough related services (Aas et al. 2018; Jing Hua Li et al. 2015; Visnjic et al. 2012):

- Solutions represent the effort to solve a customer-specific problem by adaptation and integration of products, services, and software (Raddats et al. 2019). For example, City Bank creates, through integration of banking products, counselling, and mobile/computer applications, a complex offering to suit the permanently changing client needs all around the world (Miller et al. 2002).

- Integrated solutions also interconnect products and services in accordance with customer needs, but it is not limited to the use of electronic facilities (Pistoni and Songini 2018).

- PSS focuses on sale of functions that are so-called dematerialized rather than on sale of material products. It aims to fulfil specific requirements of individual customers (Manzini and Vezzoli 2003). There are 5 PSS variations in total (Kryvinská et al. 2014; Neely 2008):

- Integration-oriented PSS, where manufacturing companies focus on services through vertical integration, i.e. on extension of the activity of e.g. retail and distribution, financial and/or advisory services, services in the area of real estate, transport services. The product ownership is still transferred to the customer. For example, they are companies in the crude oil industry that extract, refine, and manufacture petrol and, in addition to that, they provide a huge infrastructure for distribution and retail.

- Product-oriented PSS provides extra services directly relating to the product, e.g. its design and development, installation and implementation services, maintenance and support services, advisory or operational services.

- Service-oriented PSS represents integration of services into the product itself. Its ownership is however still transferred to the customer. They are, for example, smart traffic systems integrating information and telecommunication technologies into traffic engineering.

- When PSS is usage-oriented, there is a shift to services delivered through the product, whose ownership is not transferred. The manufacturing company no longer sells its products but their functions through modified distribution and payment systems, e.g. leasing, periodical payments.

- Goal-oriented PSS aims to replace a product by a service. It is, for example, the voice message service, which has replaced the need to own a recording device.

- Functional sales also focus on selling functions (e.g. an offer to wash your linen instead of offering a washing machine). However, this represents a comprehensive solution satisfying the identified customer's need with respect to the whole product or service lifetime, from a design and manufacturing to a service (Aurich et al. 2006). The supplier decides which products they will use to ensure the function, unlike leasing, where the products are specified by the customer (Sundin and Bras 2005).

- Function product is the output of a functional sale, also called the "total care product." It is used, for example, in aviation, processing, and medical industries. It is associated with different payment options. (e.g. payment for hours of its usage, periodically per year, for performance of the facility or for the provided function, e.g. for a supplied energy (Alonso-Rasgado and Thompson 2006). For example, it can also be a coffee machine if a company pays its provider for the number of coffees made, and the ownership of the coffee machine is not transferred.

- Integrated product and service engineering specifies the properties of a functional product to direct at the functions delivered to the customer and at full integration of different elements into corporate offerings to meet the customer needs better (Pistoni and Songini 2018). For example, a manufacturer provides and installs their machines at the customer's manufacturing plant; that uses them and pays the supplier for the produced quantities. If the customer does not need to produce, the supplier takes the machine back. The supplier tries to make sure that the customer uses the machines as long as possible and that they are operated with a low failure rate or with not very frequent repairs (Lingegård et al. 2012). This relationship between the customer and the supplier is also called leasing.

Many authors link implementation of servitization with transition of manufacturing company to some other PSS variant (Tukker 2004; Kryvinská et al. 2014). This transition is recommended to be 
realised successively, i.e. from realization of PSS with the lowest accent on services, eventually from already in company established PSS to the realization of particular PSS variants which are more and more orientated on services (Neely 2008). It is suitable to manage individual steps of implementation of servitization as a project (Kostalova and Tetrevova 2016).

\subsection{Services presented on the main web pages of manufacturing in the Czech Republic}

If companies want to support their growth through services, it is necessary to present their services to their customers. One of the possibilities is their presentation on web pages. The current trends in services offered by manufacturing companies in the Czech Republic were identified through an analysis of 165 web pages from the point of view of services they offer. The following variables were surveyed: the company size from the point of view of the number of employees, the type of the offered service: on the main web page (marked as the first level presentation), after clicking a tab open (second level presentation), and together with offering a product (with a product). One of the conditions of successful servitization is also creation of an independent service innovation department (Motwani et al. 2006). Therefor the existence of such department was additional monitored variable. Table 1 shows the outcomes of an analysis of presented services by their location on web pages of the researched companies.

Table 1. The frequency of the companies by level presentation of the offered service.

\begin{tabular}{ccc}
\hline Presented services & Absolute Frequency & Relative frequency \\
\hline No & 49 & $30 \%$ \\
Yes & 116 & $70 \%$ \\
\hline First level & 96 & $58 \%$ \\
Only first level & 20 & $12 \%$ \\
Second level & 86 & $52 \%$ \\
Only second level & 10 & $6 \%$ \\
Both level & 76 & $46 \%$ \\
With a product & 87 & $53 \%$ \\
Only with a product & 10 & $6 \%$ \\
All three levels & 65 & $39 \%$ \\
\hline
\end{tabular}

Table 2 shows the structure of companies according to the level of presentation of the services offered and according to the existence of the innovation department.

Table 2. The frequency of the companies by level presentation of the service and by innovation department.

\begin{tabular}{cccc}
\hline $\begin{array}{c}\text { Innovation department } \\
\text { Presented services }\end{array}$ & Yes & No & Total \\
\hline Yes & 50 & 66 & 116 \\
No & 12 & 37 & 49 \\
\hline Total & 62 & 103 & 165 \\
\hline
\end{tabular}

Table 3 shows the outcomes of an analysis of presented services and independent service innovation department by their location on web pages structured by size of the researched companies. 
Table 3. The structure of the companies by the level presentation of the offered service and by their size.

\begin{tabular}{ccccccc}
\hline Companies & $\begin{array}{c}\text { Relative } \\
\text { frequency }\end{array}$ & $\begin{array}{c}\text { Presented } \\
\text { services }\end{array}$ & $\begin{array}{c}\text { First level } \\
\text { presentation }\end{array}$ & $\begin{array}{c}\text { Second level } \\
\text { presentation }\end{array}$ & $\begin{array}{c}\text { With a } \\
\text { product }\end{array}$ & $\begin{array}{c}\text { Innovation } \\
\text { department }\end{array}$ \\
\hline Small-sized & $22 \%$ & $73 \%$ & $59 \%$ & $46 \%$ & $35 \%$ & $24 \%$ \\
Medium-sized & $37 \%$ & $66 \%$ & $57 \%$ & $57 \%$ & $59 \%$ & $30 \%$ \\
Large-sized & $41 \%$ & $73 \%$ & $58 \%$ & $51 \%$ & $57 \%$ & $52 \%$ \\
\hline Total & $100 \%$ & $70 \%$ & $58 \%$ & $52 \%$ & $53 \%$ & $38 \%$ \\
\hline
\end{tabular}

\section{Services presented on the main www page (first level presentation):}

- customer support centre, customer centre, product advisory centre, efficient service provider in the area of logistics, development and facility management, help with projects, counselling, expert consultations, tailored formulas, seller services, manuals, instructional videos,

- school for foremen, service school,

- databases, publicly accessible expert information service,

- research and development, test laboratories, custom measurement, part supplies according to drawings, transfer of technologies,

- manufacturing: contract, custom-made, according to specific customer requirements,

- e-shop, factory shop,

- payment after delivery, free shipping, money-back guarantee, product exchange, complaints,

- service: comprehensive, technical, technological, general overhauls, customer support with failures, spare parts,

- complementary customized services, comprehensive logistics services, vendors' services, product packaging, industrial park, reliable delivery.

From the point of view of the servitization status, it is interesting to study presentations of the sets of offered services by individual companies. Only one service was presented by 17 companies. More than 2 services were presented by 24 companies, out of which the most widely presented offer was that of IDIADA CZ. Their Development Department offers a wide portfolio of services from draft designs, through conceptual designs, to construction for serial production verified through technical simulations for automotive, machinery, and consumer industry customers.

Another 4 companies presented their services generally as follows: We can adapt to your requirements and find a tailored solution. We will adapt to your needs and we offer you complementary services within the area of business.

\section{Services after click opening (second level presentation):}

- customer support centre, service center, counselling, technical support, hotline, call centre, online customer support and assistance, social counselling, manuals, instructions, assembly procedures, consultations, seminars, documentation,

- courses and training, classroom and training technology rental, instructional videos, virtual tour, special tours, inspections and measurement at the customer's premises, excursions, special events, training department, environmental centre,

- calculators (medical, thermal insulation), draft solution, calculations, analyses, putting into operation, draft design, refinement, automation of manufacturing, application, implementation, new technical solutions, complete installation, electrical assembly - including an electrical safety report, custom manufacturing,

- research and development, constructional solution and development of the whole product only after its implementation,

- measurement, testing, metrological centre, laboratory (testing, application, environmental, for building materials), sample testing, product adjustments, expert opinions, diagnostics, defectoscopy, quality management, quality control, 
- service - complete, nonstop, presale, sales, after-sale, guarantee and post-guarantee, fire, technological, technical, coloristic, craftsmen; services to improve product quality, unplanned service intervention, regular service maintenance, repairs, overhauls, refurbishment, prepaid service, comprehensive product after-sale care,

- logistic service, supplying, waste disposal,

- spare parts manufacturing, diagnostics, failure solutions, maintenance, aids rental,

- information (about raw materials, products, orders), textile database, technical informatics, remote data monitoring,

- e-shop, specialized shops,

- financing, loan, insurance,

What are interesting from the point of view of the servitization level are the presented offerings of comprehensive services by two companies:

Paramo Pardubice: chemically friendly cleaning of machining technology circulatory systems, including pumping out of the used machining fluid, and arrangement of its disposal.

TOS Kuřim: Purchase of a machine from our portfolio means for us commencement of a longterm partnership with the customer. We are ready to respond flexibly to the customer's initiatives. We are aware of the fact that nonstop operation of a machine and its long lifetime is the key factor for the customer.

\section{Services connected with the product:}

- counselling and consultations, customer support, technological support, hotline,

- provision of tests, conducting laboratory and operational tests, sample testing, technical condition assessment, remote diagnostics, measurement, adjustment, declaration of properties, analyses,

- cleaning and disinfection, supplies of spare parts, repairs, inspections,

- supplies of products with appurtenances necessary for their installation, installation, shipping, order monitoring,

- technical support, machine operation, disposal of chemical substances, refurbishment, recycling,

- possibility of choosing by parameter, product in a lot of packages,

- services related to product development, development and manufacturing according to the customer's requirements, turn-key solutions, tailored formulas, development of mixtures, development of product, project design and implementation, drawing up technological procedures,

- cooperation,

- sample manufacturing

- service and repair, comprehensive technical support services, sample books, production of samples, spare parts

- special flavors, cooling boxes, drinks machines,

- logistics, logistic support.

Among the more complex offers of services presented with the product include: cleaning and disinfection of the machining space, analyses of lubricants and production of oils and fluids according to the customer's requirements.

\section{Discussion and Conclusions}

From the point of view of the relevance of the outcomes of the conducted analysis, it is necessary to point out that presentation of services was researched on the companies' web pages only. Therefore, it is theoretically possible that a company offering services with their products, does not necessarily present them on their web pages, or we might not have found them. However, if a company perceives services at least as a marketing tool leading to an increase in the company's profits and its growth, then the company most likely presents these services on their web pages. The outcomes are also affected by the fact that it is random sampling. However, the randomly selected set of companies from 
different industry areas is large enough to present the situation in the Czech Republic, and it was possible to formulate a relevant conclusion about the created hypothesis from the outcomes.

Tab. 1 shows that $70 \%$ of the monitored companies present the offered services on their web pages, and $55 \%$ of the companies present them on the main page. This score can also be understood as a slight increase in the applied services compared to 2016, when the conducted research identified $45 \%$ companies dealing with services.

Tab. 1 shows that $70 \%$ of the monitored companies present the offered services on their web pages, and $55 \%$ of the companies present them on the main page, $52 \%$ on the second level of presentations and $53 \%$ with the product. $24 \%$ of the companies present their services at one level only and $39 \%$ at all three levels. Apparently, if a company offers services, they very probably present them at as many places as possible. Tab. 2 shows that $63(38 \%)$ of the companies presented an independent service innovation department on their web pages, which is a condition of successful servitization. Therefore, we can assume that about a half of the companies presenting their services don't have an independent service innovation department (66 from 116) and they are at the beginning of the process of servitization only. From Table 3, we can assume that website presentation of services does not depend on the company's size. In all the cases it reaches about $70 \%$.

The analysis of the contents of the services implied that the largest variety of services can be found after clicking open some of the tabs on the main website page. However, with respect to the expected transition to the service-oriented business model, following the pattern of successful foreign companies, companies should present the services they offer on the main page as much as possible.

The content analysis also implied that companies in the Czech Republic are particularly trying increase the customer value and thus differentiate their offerings through the services. All the possibilities specified in Chapter 3.1 were identified, except for bundling. The thing is that companies mostly present/offer conventional services, or they develop new services that can be, with some exceptions, separated from the product and sold separately, i.e. product service, systems selling, full service, service package and installed base service. Companies exceptionally offer advanced services closely connected with the product in the way they provide the customer with ability rather than with a physical value, i.e. integrated solutions, PSS and function product. The Integrated Product business model and service engineering was not identified in any of the monitored companies, i.e. an offer of leasing was not identified. The fact that the number of companies offering more advanced services is decreasing gradually also affirms that manufacturing companies switch to a higher rate of services gradually and that most companies are still in the phase of integration of services into products aiming to fulfil marketing targets.

These outcomes testify in favour of the set hypothesis, i.e. that the companies mostly take a marketing approach to servitization, i.e. that companies have only sporadically reached the strategic approach to servitization. However, it is these companies can be a suitable example for other manufacturing companies in the Czech Republic showing how to find opportunities for servitization.

\section{References}

Aas H. Tor, Breunig J. Karl, and Hellstrom Magnus. 2018. Stages in transforming product-to service-oriented business models. Paper presented at the Conference ISPIM Connects Fukuoka, Fukuoka, Japan, December, pp. 1-12. Available online: https://www.researchgate.net/publication/328963894_Stages_in_transforming_product-_to_serviceoriented_business_models; www.ispim.org (accessed on 12 January 2020)

Alonso-Rasgado M. Teresa., Thompson G. 2006. A rapid design process for Total Care Product creation. Journal of Engineering Design: 17(6), 509-531. https://doi.org/10.1080/09544820600750579.

Aurich C. Jan, Fuchs C., and Wagenknecht C. 2006. Life cycle-oriented design of technical Product-Service Systems. Journal of Cleaner Production: 14(17), 1480-1494. https://doi.org/10.1016/j.jclepro.2006.01.019.

Baines S. Tim, Lightfoot Howard, Benedettini Ornella, and Kay J. M. 2009. The servitization of manufacturing: A review of literature and reflection on future challenges. Journal of Manufacturing Technology Management: 20(5), 547-567. https://doi.org/10.1108/17410380910960984.

Balasova Veronika. 2019. Možnosti implementace servitizace v českých podnicích. Dimploma thesis. Univerzita Pardubice, Czech Republic. 
Desmet Steven., Dierdonc V. Roland, Looy V. Bart, and Gemmel Paul. 2003. Servitization: or why services management is relevant for manufacturing environments. Essex: Pearson Education.

Eggert Andreas, Ulaga Wolfgang, Frow Pennie, and Payne Adrian. 2018. Conceptualizing and communicating value in business markets: From value in exchange to value in use. Industrial Marketing Management: 69, 8090. https://doi.org/10.1016/j.indmarman.2018.01.018.

Friedel Libor. 2019. Servitizace - strategie pro služby s přidanou hodnotou. Available online: https://www.liborfriedel.cz/servitizace-strategie-sluzby-s-pridanou-hodnotou/ (accessed on 12 January 2020).

Jackson W. Ralph, Neidell A. Lester, and Lunsford A. Dale. 2000. An empirical investigation of the differences in goods and services as perceived by organizational buyers. Industrial Marketing Management: 24(2), 99-108. https://doi.org/10.1016/0019-8501(94)00037-W.

Jelinkova Martina, Lostakova Hana, and Pakostova Eva. 2018. Tools for Creating Positive Reputation with Customers for Chemical Industrial Enterprises. Paper presented at the 10th International Scientific Conference "Business and Management 2018", Vilnius, Lithuania, May 3-4, pp. 428-435.

Jing Hua Li, Li Lin, De Ping Chen, and Li Ya Ma. 2015. An empirical study of servitization paradox in China. Journal of High Technology Management Research: 26, 66-76. http://dx.doi.org/10.1016/j.hitech.2015.04.007.

Kanninen Tina, Penttinen Esko, Tinnila Markku, and Kaario Kari. 2017. Exploring the dynamic capabilities required for servitization: The case process industry. Business Process Management Journal: 23(2), $226-247$. https://doi.org/10.1108/BPMJ-03-2015-0036.

Kaňovská Lucie. 2018. Využití smart technologií ve službách průmyslových podniků. Brno: Akademické nakladatelství CERM.

Kostalova Jana, and Tetrevova Libena. 2016. Application of Project Management Methods and Tools with Respect to the Project Life Cycle and the Project Type. Paper presented at the 9th International Scientific Conference "Business and Management 2016", Vilnius, Lithuania, May 12-13.

Kryvinská N, Kaczor Sebastian, Strauss Christine, and Greguš Michal. 2014. Servitization Strategies and ProductService-Systems. Paper presented at the Conference IEEE 10th World Congress on Services-SERVICES 2014, Anchorage, Alaska, USA, June, pp. 254-260.

Lingegård Sofia, Sakao Tomohiko, and Lindahl Mattias. 2012. Integrated Product Service Engineering - Factors Influencing Environmental Performance. InTech: 1-164. https://doi.org/10.5772/33944.

Manzini E., and Vezzoli C. 2003. A strategic design approach to develop sustainable product service systems: examples taken from the 'environmentally friendly innovation' Italian prize. Journal of cleaner production: 11(8), 851-857. https://doi.org/10.1016/S0959-6526(02)00153-1.

Mastrogiacomo Luca, Barravecchia Federico, Frenceschini Fiorenzo. 2019. A worldwide survey on manufacturing servitization. International Journal of Advanced Manufacturing Technology: 103(2), 3927-3942. https://doi.org/10.1007/s00170-019-03740-z.

Miller Danny, Hope Quentin, Eisenstat Russell, Foote Nathaniel, and Galbraith Jay. 2002. The problem of solutions: Balancing clients and capabilities. Business Horizons: 45(2), 2-12. https://doi.org/10.1016/S00076813(02)00181-7.

Mootwani G. Jaideep, Gebauer Heiko, Friedli Thomas, and Fleisch Elgar. 2006. Success factors for achieving high service revenues in manufacturing companies. Benchmarking: An International Journal: 13(3), 374-386. https://doi.org/ 10.1108/14635770610668848.

Neely Andy. 2008. Exploring the financial Consequences of the Servitization of Manufacturing. Operations Management Research: 1(2), 103-118.

Oliva Rogelio, and Kallenberg Robert. 2003. Managing the transition from products to services. International Journal of Service Industry Management: 14(2), 160-172. https://doi.org/10.1108/09564230310474138.

Park Yongtae, Geum Yongjung, and Lee Hakyeon. 2012. Toward integration of products and services: Taxonomy and typology. Journal of Engineering and Technology Management: 29(4), 528-545. https://doi.org/10.1016/j.jengtecman.2012.08.002.

Pistoni Anna, and Songini Lucrezia. 2018. Servitization strategy and managerial control. North America: Emerald Publishing.

Raddats Chris, Kowalkowski Christian, Benedettini Ornella, Burton Jamie, and Gebauer Heiko. 2019. Servitization: A contemporary thematic review of four major research streams. Industrial Marketing Management: 83, 207-223. https://doi.org/10.1016/j.indmarman.2019.03.015. 
Stremersch Stefan, Wuyts Stefan, and Frambach T. Ruud. 2001. The purchasing of full-service contracts: An exploratory study within the industrial maintenance market. Industrial Marketing Management: 30(1), 1-12. https://doi.org/10.1016/S0019-8501(99)00090-5.

Sundin Erik, and Bras Bert. 2005. Making functional sales environmentally and economically beneficial through product remanufacturing. Journal of Cleaner Production: 13(9), 913-925. https://doi.org/10.1016/j.jclepro.2004.04.006.

Tellus Institute. 1999. Servicizing: The Quiet Transition to Extended Product Responsibility, Tellus Institute, Boston, MA. Available online: https://www.tellus.org/tellus/publication/servicizing-the-quiettransition-to-extended-product-responsibility (accessed on 12 January 2020).

Tukker Arnold. 2004. Eight Types of Product-Service System - Eight Ways to Sustainability? Experiences from SUSPRONET. Business Strategy and the Environment: 13, 246-260. https://doi.org/10.1002/bse.414.

Vandermerwe Sandra, and Rada Juan. 1988. Servitization of business: Adding value by adding services. European Management Journal: 6(4), 314-324. https://doi.org/10.1016/0263-2373(88)90033-3.

Visnjic Ivanka, Neely Andy, and Wiengarten Frank. 2012. Another performance paradox? A refined view on the performance impact of servitization. SSRN Electronic Journal: 1-30. https://doi.org/10.2139/ssrn.2117043.

Vlckova Vladimira, and Balasova Veronika. 2019. An analysis of the Possibilities of Application of Servitization at Selected Manufacturing Companies. Paper presented at the International Conference on Metallurgy and Materials, Brno, Czech Republic, May 22-24, pp. 1873-1879.

Weijiao Wang, Lai Kee-hung, and Shou Yongyi. 2018. The impact of servitization on firm performance: a metaanalysis. International Journal of Operations $\mathcal{E}$ Production Management: 38(4), 1562-1588. https://doi.org/10.1108/IJOPM-04-2017-0204. 